\title{
Stope boundary optimization for an underground copper deposit using mixed integer linear programming based algorithm
}

Optimal ore body boundary and production area geometry (Stope) are essential to maximize the profit from an underground mining project subject to inherent physical, geotechnical and geological constraints. Number of researches have been introduced for stope boundary optimization but true optimal solution in three dimensional spaces is still out of reach. This article proposed a computer programming based optimization model using mixed integer linear programming based algorithm that incorporate stope boundary optimization with varying cost of mining and selling price of the metal. An actual ore body model was taken as case study to implement the algorithm in real mining scenario. In validation study, it is observed that, by using proposed model, the profit can be increased by $10 \%$ $15 \%$ as compared to the present stoping practice. Simulating the optimal stope boundary by changing the various cost and price parameters helps to opt the best possible option for a given mining scenario to make most realistic plan.

Keywords: Stope, boundary, modelling, algorithm, ore body.

\subsection{Introduction}

$\mathrm{E}$ conomic potential evaluation of a mineral deposit is one of the primary tasks carried out at planning stage and in fact continues throughout mine life by mining engineers. Mining is done in stage by stage through a collection of activities including exploration, ore body modelling, grade modelling, valuation of the deposit, mining method selection, mode of entry, mine development, stope preparation, drilling and blasting, ore extraction and transportation, milling and marketing of final products.

Blind peer reviews carried out

Prof. Gopinath Samanta, PhD Scholar, Prof. Suranjan Sinha, Professor, Indian Institute of Engineering Science \& Technology, Shibpur, Howrah, Prof. Tapan Dey, M.Tech, Indian Institute of Technology Bombay, Mumbai and Biswajit Samanta, Professor, Department of Mining Engineering, Indian Institute of Technology, Kharagpur, India. E-mail: gopiiitkgp.samanta65@gmail.com / suranjan1980@gmail.com / tapan.besu@gmail.com / samantab@mining.iitkgp.ac.in
Optimization in each stage is very much important to maximize the natural resource extraction as well as for reduction in cost and maximization of profit from the resources. Stope boundary optimization is one of the major concerns for optimum extraction of the deposit from an underground mine and to get maximum profit. For very long, a plenty of researches have been reported on opencast pit optimization and number of algorithms have been developed over the years and the true solution is guaranteed with commercial computer package like Whittle. Unlike open pit mining, there is a limited research documented for the optimization of the stope geometry in underground mining. Apart from the quantity of research, the quality of the works carried out and the tools available for optimization of underground metalliferous mines, are as expected, much lower than that for their open pit counterpart (Ataee-Pour, 2000). There are various reasons for the lack of research in underground mine optimization. These include generality, complexity and acceptability (Ovanic and Young, 1995).

Stope geometry optimization can be described as the decision of what part of a mineral resource should be mined (and what part should be left in place) in order to maximize the return from the stope as well as from the project. It has long been realized that mining simply every part of an ore body with a grade higher than zero is not economical and will not lead to a successful mining operation. By selecting a cutoff grade, it makes sure that each block of ore pays for its own mining. However, depending on the ore body configuration and grade distribution in an ore body, cutoff grade value can be dynamically determined for different parts of the ore body to maximize the profit. Therefore, optimization of ore body boundary for varying grade and mining cost is essential for profit maximization from this deposit. Due to the lack of optimization tools the underground mine planning process can be very time consuming. Especially the design of stope at different cut-off grades can take a significant amount of time. As a consequence of the process being very time consuming, underground mine optimization is in many cases not carried out properly resulting in sub-optimal project performance and loss of potential profit. 
Thus, to understand the advancement in stope boundary optimization, previous research works have been extensively surveyed and an efficient computer programming has been developed using mixed integer linear programming based algorithm to evaluate the optimum stope boundary in an underground mine. The optimization procedure is elaborately discussed.

Optimization model formulation with flow chart and equations are also stated in this text. The developed model is also tested in a real data collected from Indian underground copper mine. Ore body model prepared in Date Mine software is used as input in optimization model. The optimization output for ore body and individual stope are noted and compared to real output from existing stope design practice in the mines. Different scenario analyses are also conducted for varying mining cost and copper price along with a comparative study with the output using original parameters.

\subsection{Previous research works}

An extensive literature survey has been conducted to understand the process of stope design in underground mining and to study the different models and algorithms for optimum extraction of minerals. Some of the remarkable algorithms, which are already being developed and implemented to determine optimized stope layout, their features and drawbacks, are discussed below.

Ovanic and Young (1995) proposed a mixed integer programming based formulation which is known as type-two special ordered sets. The algorithm uses two piecewise linear cumulative functions and identifies the optimized start and end points for mining. The algorithm is applicable on regular or irregular sized mining blocks within the ore body model. However, the limitation of the approach is that it optimizes the stope boundary on single dimension. Thus, the algorithm generates a partial optimal solution of the problem. Griceo and Dimitrakopoulos (2007) also presented a MILP based optimization model. In this approach, the entire ore body is first divided into number of layers, panels and rings and then optimize number of rings for which the metal content is maximized is calculated. The geological uncertainty may also be considered in the model. However, based on the size of mining blocks, the algorithm considers the block into predefined rings. As a result, the model deviates from the optimality.

A novel heuristic approach was presented by Sandanayake, Topal and Ali (2015) to determine optimized stope layout for an underground mine. The algorithm generates a set of all possible stopes to provide the solution which maximizes the economic value of the stope under physical and geotechnical constraints. The computational complexity was explained and established in this article to solve the stope layout problem, specifically for generating unique and non-overlapping stopes. This case study reflects the success in addressing the computational complexity of the problem. Ataee-Pour (2000 and 2004) demonstrated a heuristic method based on the maximum value neighborhood (MVN) approach. The algorithm identifies a set of possible neighborhoods for each mining block in the ore body model and depending on the economic value; the algorithm identifies the optimal neighborhood. For a particular mining block as starting point, MVN offers robust solution to the complex stope optimization problem. However, the limitation is that if the starting location of a block model is varied, the MVN algorithm produces different solutions to the model. Sens and Topal (2009) also contributed a heuristic approach for stope layout optimization.

The algorithm is capable to incorporate variable stope sizes for stope boundary or layout development in threedimensions. It eliminates the limitations of floating stope algorithm in the overlapping stopes within the solution. However, the algorithm generates only one set of nonoverlapping stopes depending upon maximum economic value as a criterion. But in practical, multiple combinations of nonoverlapping stope sets exist, and the optimal solution must be selected among these combinations. Another heuristic method was developed by Copland and Nehring (2016) for design and optimization of stope boundary along with an extraction scheduling in a single model. They realize and emphasize the need of integrated approach. The model provides a basis for future work in the application of integer programming to other areas of underground optimization. Bai, Marcotte and Simon (2014) proposed a new heuristic sublevel mining stope optimizer. It looks for suitable raise location for stope and different design constraints for optimization. The optimization is done on the locations and lengths of raises using genetic algorithms. For each raise, a local network is defined in cylindrical coordinates around the raise such as to impose the design constraints. It was found that the multiple raises approach led to significantly improved economic value as compared to the single-raise stope optimizer, and the dilution is also substantially reduced compared to the singleraise case.

Alford (1995) proposed floating stope algorithm which searches the ore and waste mining blocks within the ore body model. The maximization of ore tonnage, grade, metal content or economic value is considered for optimizing the stope layout problem. However, the algorithm generates overlapping stopes within the ore body and it requires manual adjustment on optimization model. As a result, it produces a sub-optimal solution. Cawrse (1995 and 2001) also contributed a Multiple Pass Floating Stope Process (MPFSP). The MPFSP identifies stope envelopes within the ore body. However, it does not address the limitation of "floating stope" algorithm.

Graph theory and network flow based algorithm was proposed by Bai, Marcotte and Simon (2012). The algorithm defines a cylindrical coordinate system around a specified 
raise location and optimizes the stope profit. The authors compared the performance of the algorithm with the floating stope algorithm and obtained better solutions. However, this algorithm is limited to small mineralized ore bodies and sub-level stoping mining method. Little, Knights and Topal (2013) presented an optimal stope design, and long-term production scheduling algorithm and demonstrated the benefits of using an integrated optimization approach for mine planning. Four deferent algorithms were studied by Erdogana, Ciglab et al. (2017) and their applicability was checked in an underground mine where sublevel stoping mining method was adopted. The selected algorithms were floating stope, maximum value neighborhood, and two special applications developed by Sens and Topal and Sandanayake and Topal. They compared these algorithms capabilities, limitations 'with respect to stope optimization results from an existing underground mine. The results showed that none of them can give a true optimum solution; they provide only approximate solutions in three dimensions.

\subsection{Materials and methods}

The resource modelling is one of the key requirements for optimization of the stope boundary. Resource modelling is basically a block model in three dimensional spaces along $\mathrm{X}, \mathrm{Y}$ and $\mathrm{Z}$ directions which are along the strike, width and height of the ore body respectively. By using suitable grade estimation technique, the block model is assigned with grade to generate the ore body model. The proposed model optimizes each dimension based on economic value which is obtained from each block grade, tonnage, various mining cost and selling price of the metal. Fig. 1 presents a flow chart illustrating basic methodology.

\subsection{Mathematical model Formulation}

Stope boundary optimization model formulation is done to determine optimal starting and end point of each dimension of the ore body model. Trough position, direction of trough, and stope wall are also considered to determine the optimal stope boundary. Finally, the model develops an

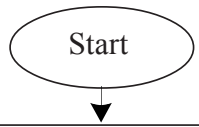

Parameters: Define all the necessary parameters related to orebody modelling, price, cost, trough position, trough angle, inclined wall etc.

\section{$\nabla$}

Decision variables: Define all the decision variables related to starting and ending point of the stope at each direction, adjacent layers, stope boundary at each direction, trough position, trough angle, angle of the inclined wall etc.

Constraints: Define all the constraints related to starting and ending point of the stope at each direction, adjacent layers, stope boundary at each direction, volume of the ore body under the trough area trough position, trough angle, angle of the inclined wall etc.

Objective function: Define objective function related to price of the extracted mineral, cost of extraction of ore, hence total profit

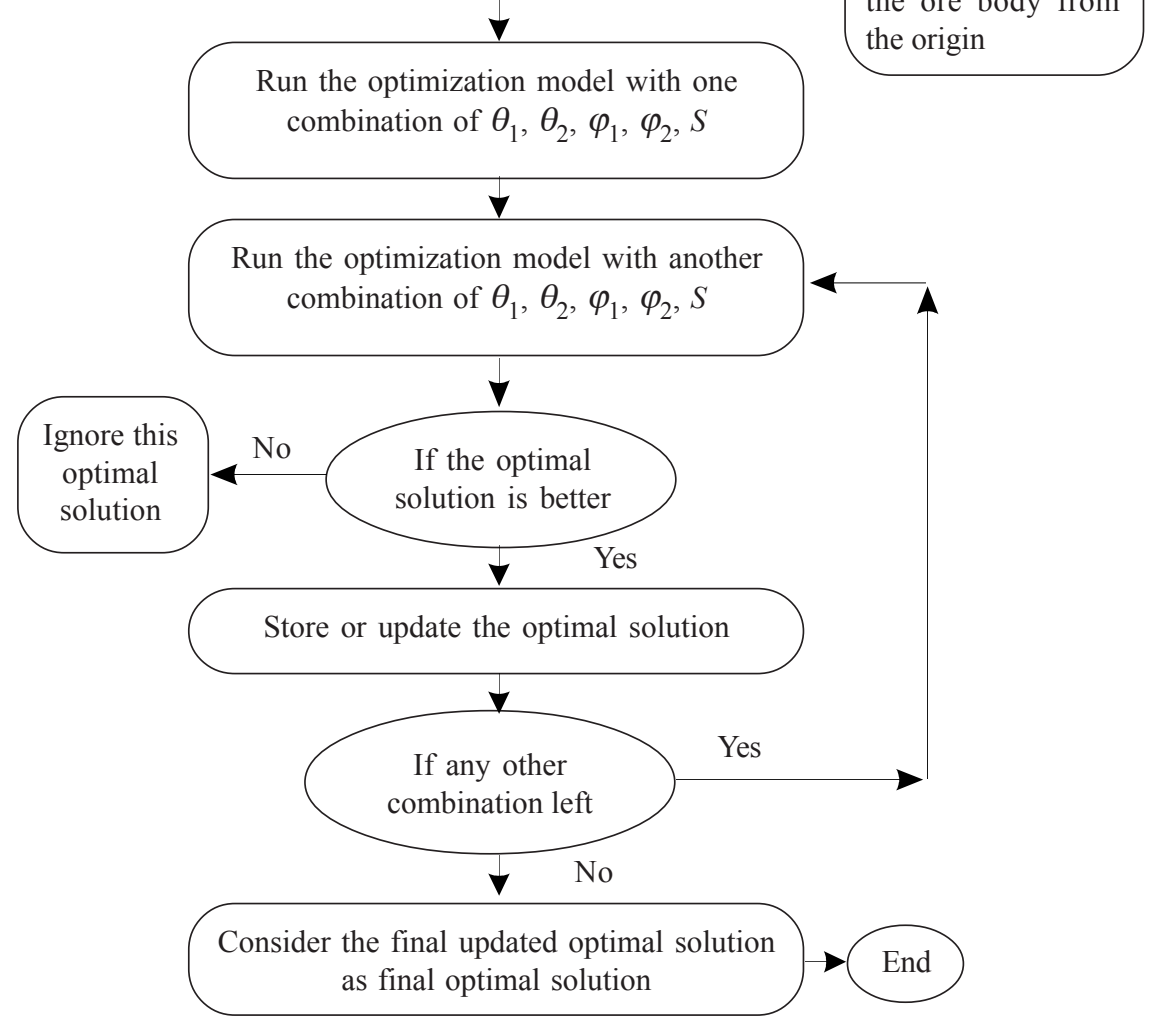

Fig.1 Flow chart of model formulation for stope optimization
Where:

$\theta_{1}=$ Trough angle towards hang wall ranging from 50 to 70 degree with 5 degree increment

$\theta_{2}=$ Trough angle towards foot wall ranging from 50 to 70 degree with 5 degree increment

$\varphi_{1}=$ Angle of the wall at the starting point along the strike ranging from 30 to 90 degree with 5 degree increment

$\varphi_{2}=$ Angle of the wall at the ending point along the strike ranging from 30 to 90 degree with 5 degree increment

$S=$ Trough position along the width of the ore body from the origin 
optimal stope layout by maximizing the total economic value (profit) subject to the physical and geotechnical constraints. The following notations are defined for explaining the steps of the algorithm.

\subsubsection{Assumptions}

The following assumptions are made for development of the optimization model:

Position of the trough is assumed to be at the middle of the ore body or user defined position.

Trough angle is considered in between 50 and 70 degree from the horizontal.

Angle of the wall at start point and at end point are considered in between 30 and 130 degree from the horizontal.

Grade of non-minable ore zone due to trough is considered as average grade.

\subsubsection{Parameters}

$V_{B}=$ Volume of each block.

$S G=$ Specific gravity of ore.

$P M=$ Metal price per tonne.

$F C, V C, M C=$ Fixed cost, variable cost and processing cost per tonne of metal respectively for each block.

$P C_{i j k}=$ Cumulative profit coefficient for each block.

$\theta_{1}, \theta_{2}=$ Trough angle towards hangwall and footwall respectively are in between 50 and 70 degree from horizontal with 5 degree increment.

$\varphi_{1}, \varphi_{2}=$ Angle of the wall at the starting point and the ending point respectively in between 30 and 130 degree from horizontal with 10 degree increment.

$S=$ Trough position along the width of the ore body.

$W=$ Width of the ore body.

$R_{i j k}=$ Position of each block in ore body model.

$G_{h}, G_{f}=$ Average grade under the trough towards hangwall and footwall respectively.

$V_{t}, V_{l}=$ Volume due to inclined wall at the tailing end and leading end respectively.

$G_{t}, G_{l}=$ Average grade due to inclined wall at the tailing end and leading end respectively

\subsubsection{Preprocessing}

Cumulative profit factor based on the price and cost for each dimension is determined below

$$
\begin{aligned}
P C_{i j k}= & \sum_{i=1}^{i}\left(V_{B} * S G * G_{i j k} * P M-V_{B} * S G *\right. \\
& \left.F C-V_{B} * S G * V C-V_{B} * S G * M C\right)
\end{aligned}
$$

Average grade under the trough towards hangwall based on the trough angle is determined bellow.

$$
G_{h}=\frac{\left(\sum_{i=1}^{n} \sum_{j=S_{m}}^{m} \sum_{k=1}^{H_{h}} G_{i j k}\right)}{n *\left(m-S_{m}\right) * H_{h}}
$$

Where, $H_{h}$ is the sequence of block number at $(W-S) * \tan \theta_{1}$ position and $S m$ is the sequence of block number at trough position.

Average grade under the trough towards footwall on the trough angle is determined below.

$$
G_{f}=\frac{\left(\sum_{i=1}^{n} \sum_{j=1}^{S_{m}} \sum_{k=1}^{H_{f}} G_{i j k}\right)}{n * S_{m} * H_{h}}
$$

Where, $H_{f}$ is the sequence of block number at $\mathrm{S} * \tan \theta_{1}$ position and $S m$ is the sequence of block number at trough position.

Average grade due to inclined wall at the tailing end is determined below.

$$
G_{t}=\frac{\left(\sum_{i=1}^{L_{t}} \sum_{j=1}^{m} \sum_{k=1}^{l} G_{i j k}\right)}{L_{t} * m * l}
$$

Where, $L_{t}$ is the sequence of block number at $\frac{H}{\tan \varphi_{1}}$ position.

Average grade due to inclined wall at the leading end is determined below.

$$
V_{t}=\left(\frac{1}{2} * \frac{H}{\tan \varphi_{1}} * H * W\right)
$$

Where, $L_{l}$ is the sequence of block number at $\frac{H}{\tan \varphi_{2}}$ position.

Volume due to inclined wall at the tailing end is determined based on the angle at tailing end below.

$$
V_{t}=\left(\frac{1}{2} * \frac{H}{\tan \varphi_{1}} * H * W\right)
$$

Volume due to inclined wall at the leading end is determined based on the angle at leading end below.

$$
V_{l}=\left(\frac{1}{2} * \frac{H}{\tan \varphi_{2}} * H * W\right)
$$

\subsubsection{Decision variables}

$x_{i j k}=$ Starting point of the stope

$y_{i j k}=$ Ending point of the stope

$o_{i j k}=$ Boolean variable to consider maximum one block at the starting point of the stope

$p_{i j k}=$ Boolean variable to consider maximum to one block at the ending point of the stope

$b_{j k}=$ Start point of the boundary

$c_{j k}=$ End point of the boundary

\subsubsection{Decision expression}

$v_{h}=$ Volume under the trough towards hangwall

$v_{f}=$ Volume under the trough towards footwall

\subsubsection{Objective function}

Maximize the total profit from the stope boundary by extracting the ore 


$$
\begin{aligned}
& \left(\sum_{i=1}^{n} \sum_{j=1}^{m} \sum_{k=1}^{l}\left(P C_{i j k} *\left(y_{i j k}-x_{i j k}\right)\right)\right)-P M \\
& *\left(v_{h} * S G * G_{h}+v_{f} * S G * G_{f}+V_{t} * S G * G_{t}+V_{l}\right. \\
& \left.* S G * G_{l}\right)+(F C+V C+M C) \\
& *\left(S G * v_{h}+S G * v_{f}+S G * V_{t}+S G\right. \\
& \left.* V_{l}\right)
\end{aligned}
$$

\subsubsection{Constraint}

Starting point for each dimension will be considered exactly one full block.

$$
\begin{aligned}
& \sum_{i=1}^{n} x_{i j k} \leq 1 \forall j, k \\
& \sum_{i=1}^{n} o_{i j k} \leq 1 \forall j, k
\end{aligned}
$$

Ending point for each dimension will be considered exactly one full block.

$$
\begin{aligned}
& \sum_{i=1}^{n} y_{i j k} \leq 1 \forall j, k \\
& \sum_{i=1}^{n} p_{i j k} \leq 1 \forall j, k
\end{aligned}
$$

Starting boundary should be before the ending boundary of each dimension

$$
\sum_{i=1}^{n}\left(R_{i j k} * p_{i j k}-R_{i j k} * o_{i j k}\right) \geq 0 \forall j, k
$$

Starting and ending with non-zero would be exactly same of each dimension

$$
\sum_{i=1}^{n}\left(p_{i j k}-o_{i j k}\right)=0 \forall j, k
$$

Boundary of the stope will be from the start point to the end point of each dimension

$$
\begin{aligned}
& \sum_{i=1}^{n} R_{i j k} * x_{i j k}-b_{j k}=0 \forall j, k \\
& \sum_{i=1}^{n} R_{i j k} * y_{i j k}-c_{j k}=0 \forall j, k
\end{aligned}
$$

Trough angle towards the hang wall and footwall will be between minimum and maximum given parameters values.

$$
\begin{aligned}
v_{h}= & \left(\frac { 1 } { 2 } * ( W - S ) * \operatorname { t a n } \theta _ { 1 } * ( W - S ) * \left(c_{j k}\right.\right. \\
& \left.\left.-b_{j k}\right)\right) \forall j=1, k=1 \\
v_{f}= & \left(\frac{1}{2} *(S) * \tan \theta_{2} *(S) *\left(c_{j k}-b_{j k}\right)\right) \forall j \\
= & 1, k=1
\end{aligned}
$$

\subsubsection{Nonnegative and Boolean variable constraints}

$$
\begin{aligned}
x_{i j k} & \geq 0, y_{i j k} \geq 0, b_{j k} \geq 0, c_{j k} \geq 0,0_{i j k} \\
& =(1,0), p_{i j k}=(1,0)
\end{aligned}
$$

\subsection{Implementation of the optimization model}

4.1 Filed DATA COLLECTION AND PREPARATION OF BLOCK MODEL

The model was tested in a real block model prepared in Data Mine software for an Indian underground copper mine. The deposit is located at J.hunjhunu district of Rajasthan state having latitude $28^{\circ} 0^{\prime} 54^{\prime \prime}$ north and longitude $75^{\circ} 46^{\prime} 32^{\prime \prime}$ east. The blast hole stoping method is used in this mine. The mine is working between the depths of about $100 \mathrm{~m}$ to $500 \mathrm{~m}$ from the surface. The study area was taken between the level $70 \mathrm{ML}$ to $300 \mathrm{ML}$ along $200 \mathrm{~m}$ strike length in north section of the deposit. The exploration drilling was conducted from footwall drive with fan pattern having interval of $25 \mathrm{~m}$. Due to the confidentiality, the data were provided only for a certain part of the ore body. Eight drill holes section's data were collected for ore body modelling. The drill holes plan and section are shown in Figs.2 and 3.

The block modelling was done for a regularized block model with $5 \mathrm{~m} \times 5 \mathrm{~m} \times 5 \mathrm{~m}$ along $\mathrm{x}, \mathrm{y}, \mathrm{z}$, directions respectively. The total number of block in the model is 85184 nos. The sectional view of the block grade model and with drill hole traces are shown in Fig. 4.

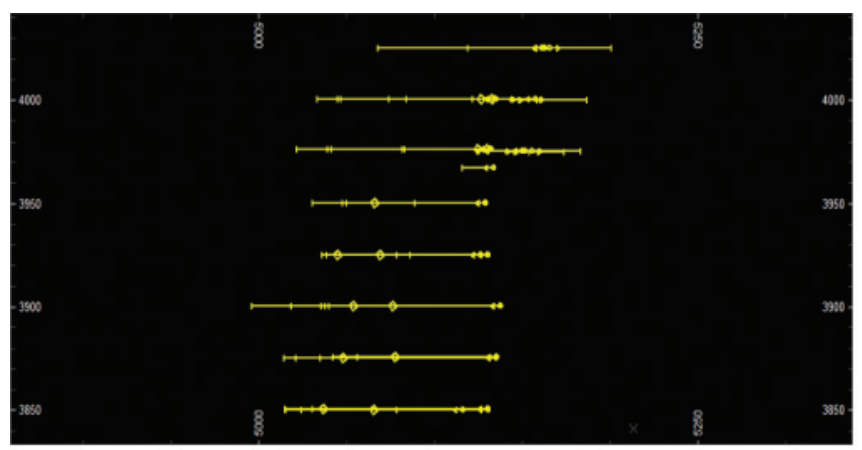

Fig.2 Plan of drill holes

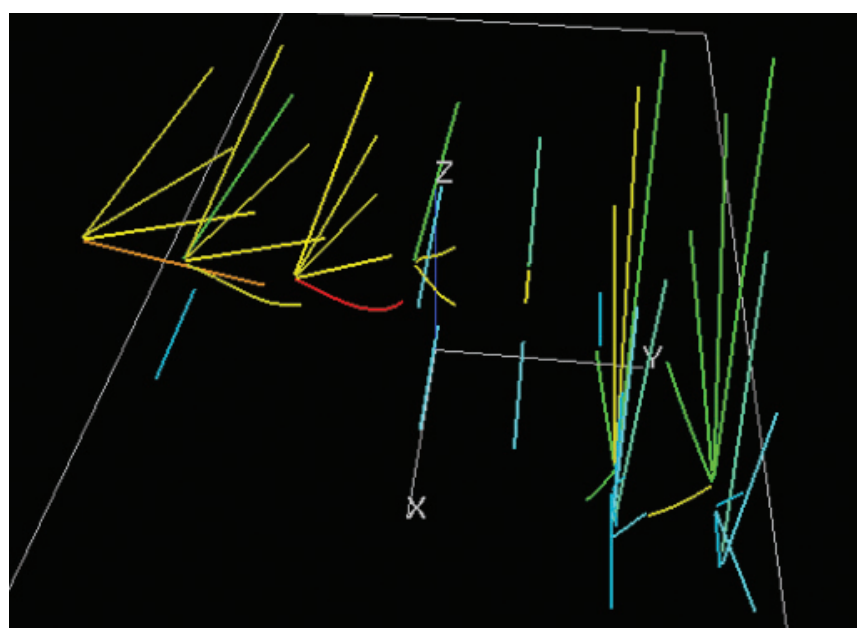

Fig.3 Section of drill holes 


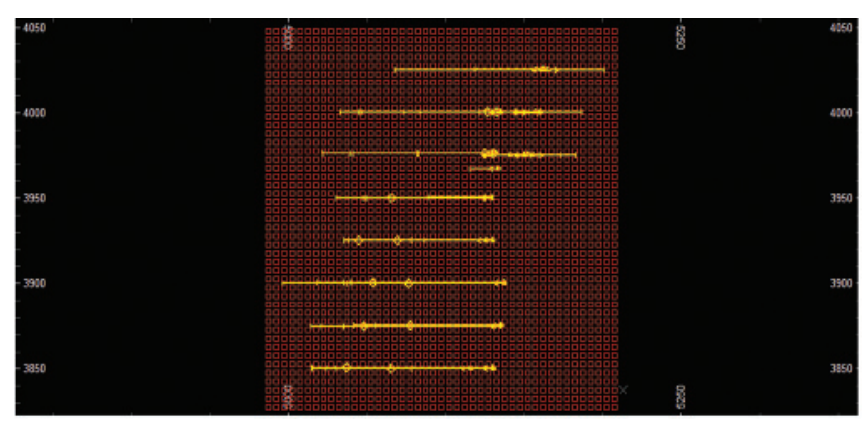

Fig.4 Block grade model with drill holes

As copper in this deposit is the primary precious metal, only $\mathrm{Cu}$ grade was considered for optimization model. The tonnage against various grades obtained from block grade model are indicated in Fig.5.

\begin{tabular}{|c|c|}
\hline Grade (\%CU) & Tonnage (MT) \\
\hline 0.5 & 2.74 \\
\hline 0.7 & 2.05 \\
\hline 0.9 & 1.85 \\
\hline 1.1 & 1.46 \\
\hline 1.3 & 1.3 \\
\hline 1.49 & 0.93 \\
\hline 1.7 & 0.69 \\
\hline 1.9 & 0.47 \\
\hline 2.09 & 0.29 \\
\hline 2.29 & 0.17 \\
\hline 2.49 & 0.11 \\
\hline 2.7 & 0.06 \\
\hline 3.33 & 0.15 \\
\hline
\end{tabular}

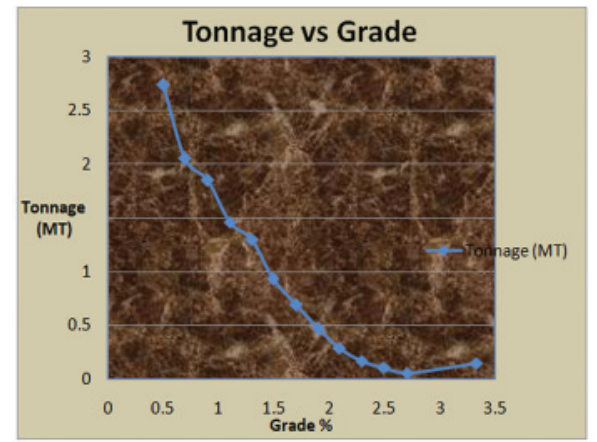

Fig.5 Tonnage Vs curve

The proposed model is capable to optimize total ore body in different scenario as well as can be able to optimize individual stope boundary. In first step, the model tested in total ore body to determine the optimal boundary, the ore contained and the metal contained in the ore body. The maximum profit was also determined from this optimization process for the whole ore body. The minimum and maximum grade of ore are $0 \%$ and $6.64 \% \mathrm{Cu}$ respectively. The material specific gravity is considered as 3.0 tonne $/ \mathrm{m}^{3}$. The grade value for each block was estimated by reserve estimation process. The revenue from each block was calculated from the metal contain in this particular block and it is sale value into the market. The input parameters considered for the stope boundary optimization model are stipulated in the Table 1.

TABle 1: Parameters USED For Optimization MOdel

\begin{tabular}{lcc}
\hline Different cost parameter & Unit & Quantity \\
\hline $\begin{array}{l}\text { Mining fixed cost per tonne of } \\
\text { metal produced }\end{array}$ & Rs. & $1,35,700$ \\
$\begin{array}{l}\text { Mining variable cost per tonne of } \\
\text { metal produced }\end{array}$ & Rs. & 58,600 \\
$\begin{array}{l}\text { Concentrator cost per tonne of } \\
\text { metal produced }\end{array}$ & Rs. & $1,45,600$ \\
$\begin{array}{l}\text { Concentrator recovery } \\
\text { Selling price per tonne of copper }\end{array}$ & Rs. & $4,45,800$ \\
\hline
\end{tabular}

The optimal ore body boundary output of the total ore body is indicated in Table 2 and Fig.6.

Mining method adopted in this case study is blast hole stoping method. Depending on the stability of the stope, the dimensions of the stope block were determined. The maximum allowable block dimensions are indicated in Table 3 .

Keeping in view, the whole ore body was divided into two stopes block. The optimized boundary and maximization of the profit were calculated for individual block. It is observed that ore as well as metal content along with profit is more for stope block-S1 than S2, the optimal stope block boundary outputs are presented in Table 4 and Figs.7 and 8.

As stope block-S1 and S2 were already mined out, the model outputs were compared to the actual mined with

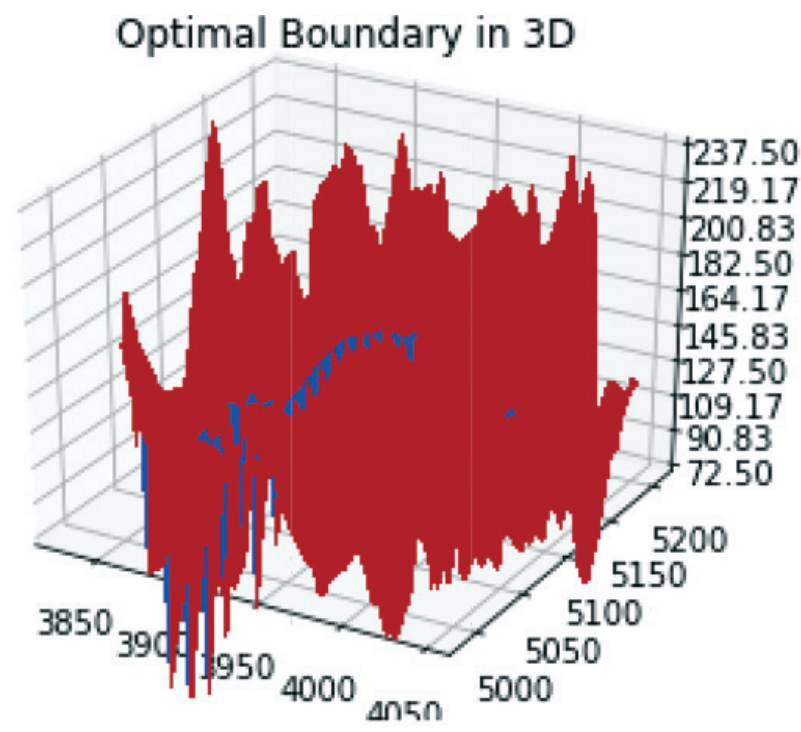

Fig.6: Optimal ore body boundary diagram of total ore body

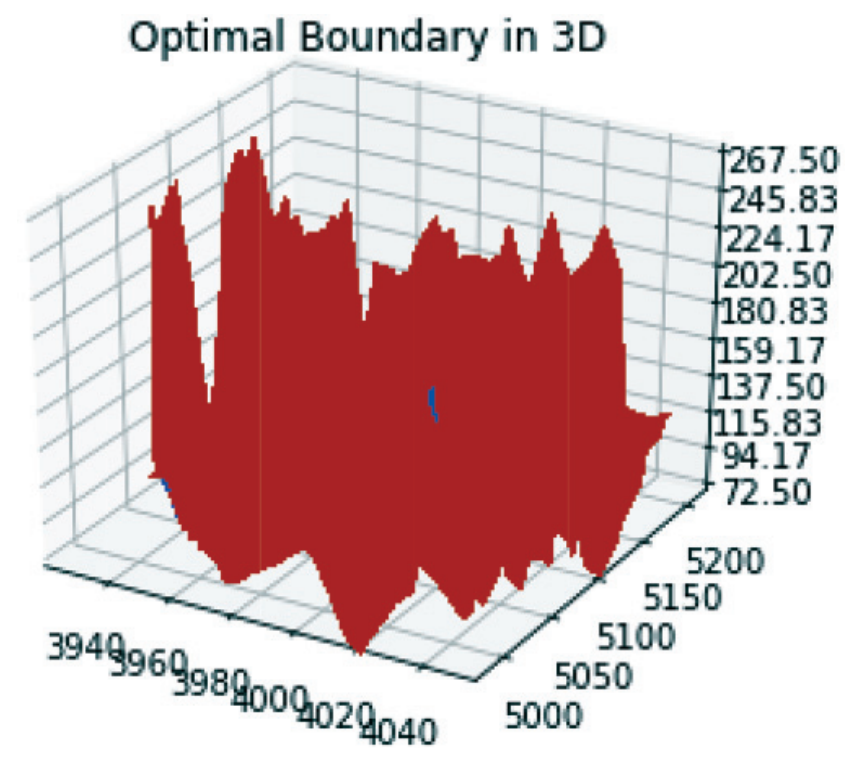

Fig.7: Optimal stope block boundary diagram of block-S1 
conventional stope design technique. The results are stated in a tabular form and the comparison of the stope block-S1 and S2 outputs with the original stope design are presented in Tables 5 and 6.

\section{Optimal Boundary in 3D}

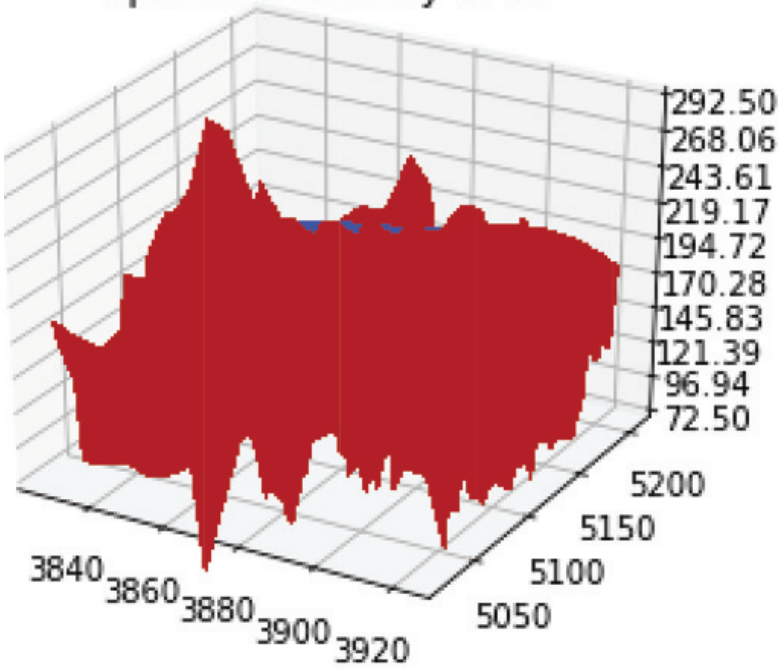

Fig.8 Optimal stope block boundary diagram of block-S2

TABLE 2: Optimal OUTPUT OF TOTAL OREBODY

\begin{tabular}{lcc}
\hline Output parameter & Unit & Quantity \\
\hline Ore tonnage & M T & 7.50 \\
Metal & M T & 0.10 \\
Grade $(\mathrm{Cu})$ & $\%$ & $1.34 \%$ \\
Revenue (Rs.) & Cr. & 2147.06 \\
\hline
\end{tabular}

TABle 3: Dimension of STOPE BLOCK

\begin{tabular}{lcc}
\hline Direction & Unit & Length \\
\hline Along strike & $\mathrm{m}$ & 100 \\
Along width of the ore body & $\mathrm{m}$ & 50 \\
Height & $\mathrm{m}$ & 60
\end{tabular}

Table 4: Optimal output of EACH STOPE Block

\begin{tabular}{lccc}
\hline Output parameter & Unit & $\begin{array}{c}\text { Quantity } \\
(\text { Block-S1) }\end{array}$ & $\begin{array}{c}\text { Quantity } \\
(\text { Block-S2) }\end{array}$ \\
\hline Ore tonnage & M T & 5.02 & 2.78 \\
Metal & M T & 0.072 & 0.032 \\
Grade (Cu) & $\%$ & $1.43 \%$ & $1.15 \%$ \\
Revenue (Rs.) & Cr. & 1644.49 & 560.54 \\
\hline
\end{tabular}

TABle 5: CoMPARATIVE ANALYSIS WITH MINE AND OPTIMAL MODEL OUTPUTS FOR STOPE BLOCK-S1

\begin{tabular}{lccc}
\hline Output parameter & Unit & $\begin{array}{c}\text { Quantity } \\
\text { from mines }\end{array}$ & $\begin{array}{c}\text { Quantity } \\
\text { from model }\end{array}$ \\
\hline Ore tonnage & M T & 4.39 & 5.02 \\
Metal & M T & 0.063 & 0.072 \\
Grade $(\mathrm{Cu})$ & $\%$ & $1.44 \%$ & $1.43 \%$ \\
Revenue (Rs.) & $\mathrm{Cr}$. & 1454.91 & 1644.49 \\
\hline
\end{tabular}

TABle 6: Comparative ANALYSIS With MINE AND OPTIMAL MODEL OUTPUTS FOR STOPE BLOCK-S2

\begin{tabular}{lccc}
\hline Output parameter & Unit & $\begin{array}{c}\text { Quantity } \\
\text { from mines }\end{array}$ & $\begin{array}{c}\text { Quantity } \\
\text { from model }\end{array}$ \\
\hline Ore tonnage & M T & 2.47 & 2.78 \\
Metal & M T & 0.028 & 0.032 \\
Grade $(\mathrm{Cu})$ & $\%$ & $1.14 \%$ & $1.15 \%$ \\
Revenue (Rs.) & $\mathrm{Cr}$ & 496.05 & 560.54 \\
\hline
\end{tabular}

From these tables, it has been observed that both the stopes block values obtained from the optimization model are $10-15 \%$ more than the present manual stope design practice.

\subsection{Conclusions}

This article presents a mixed integer linear programming based algorithm which can solve an ore body boundary optimization problem for an underground mining operation. The algorithm also gives the solution for stope boundary optimization problem. The ore body block model as well as various cost parameters is used as input into optimization model which generates unique solution that maximizes the economic value of the stope layout under physical and geotechnical constraints. The algorithm describes the computational process of the optimization and implementation of the algorithm in an actual case study reflects the success of stope output by $10-15 \%$ more in profit as compared to conventional stope design. The algorithm can be successfully applied for selecting the ore body boundary as well as the individual stope boundary optimization problem.

\section{Reference}

1. Alford, C., (1995): Optimization in underground mine design, in: 25th International APCOM Symposium, 914 July, Brisbane, pp. 213-218.

2. Ataee-Pour, M., (2000): A Heuristic Algorithm to Optimize Stope Boundaries, Doctor of Philosophy University of Wollongong, New South Wales.

3. Ataee-Pour, M., (2004): Optimization of Stope limits using a heuristic approach, Mining. Technology. 113, pp. 123-128.

4. Bai, X., Marcotte, D., Simon, R., (2014): A heuristic sublevel stope optimizer with multiple raises, Journal of the Southern African Institute of Mining and Metallurgy, 114, pp. 427-434.

5. Cawrse, (2001): Multiple pass floating Stope process, in: Strategic Mine Planning Conference, 26-28 March, Perth, pp. 87-94.

6. Copland, T., Nehring, M., (2016): Integrated optimization of stope boundary selection and scheduling for sublevel stoping operations, Journal of the Southern African Institute of Mining and Metallurgy, 116, pp. 1135-1142 
7. DATAMINE Studio RM v1.1, 2015, CAE Studio 3, Software Available at www.dataminesoftware.com (accessed 20.05.2016).

8. Erdogan, G., Cigla, M., Topal, E., Yavuz, M., (2017): Implementation and comparison of four stope boundary optimization algorithms in an existing underground mine, International Journal of Mining, Reclamation and Environment, 31, pp. 389-403.

9. Grieco, N., Dimitrakopoulos, R., (2007): Managing grade risk in Stope design optimization: probabilistic mathematical programming modal and application in sublevel stoping, Mining Technology, 116, 49-57.

10. Little, J., Knights, P., Topal, E., (2013): Integrated optimization of underground mine design and scheduling, Journal of The South African Institute of
Mining and Metallurgy, 113, pp. 775-785.

11. Ovanic, J., Young, D. S., (1995): Economic optimization of Stope geometry using separable programming with special branch and bound technique, in: 3rd Canadian Conference on Computer Applications in the Minerals Industry, 22-25 October, Quebec, 1995, pp.129-135.

12. Sandanayake, Topal, Ali A., (2015): A heuristic approach to optimal design of an underground mine Stope layout, Applied Soft Computing, 30, pp.595-603.

13. Sens, J., Topal,E., (2009): A new algorithm for Stope boundary optimization, in: TheAusIMM New Leaders Conference, 29-30 April, Brisbane, pp.44-47.

14. Topal, E., Sens, J., (2010): A new algorithm for Stope boundary optimization, J. Coal Sci.Eng. 16 (2), pp.113119.

\title{
JOURNAL OF MINES, METALS \& FUELS
}

\author{
SPECIAL ISSUE \\ $\mathrm{ON}$ \\ THICK SEAM MINING \\ IN CHINA - AN UPDATE \\ Price per copy
}

Rs.500.00; $£ 50.00$ or $\$ \mathbf{8 0 . 0 0}$

\author{
For copies please contact: \\ The Manager \\ Books \& Journals Private Limited \\ Moon Plaza (2A, 2nd Floor), \\ 62 Lenin Sarani, Taltala, Kolkata 700013 \\ e-mail: bnjournals@gmail.com; pradipchanda@yahoo.co.uk; \\ www.jmmf.info $\bullet$ Mob: +919239384829
}

